\title{
EL SIGNIFICADO DE LA REFORMA PROCESAL PENAL EN HONDURAS DESDE UNA PERSPECTIVA DE POLÍTICA CRIMINAL: UNA EXPERIENCIA A COMPARTIR'
}

\author{
RIGOBERTO CUÉLLAR CRUZ \\ Doctor en Derecho \\ por la Universidad Jaume I de Castellón de la Plana, España
}

\section{Introducción}

\begin{abstract}
A
fin de poder evaluar debidamente la certeza o no de una reforma legislativa, sobre todo cuando la misma implica cambios de la envergadura implícita en nuestra reciente reforma procesal penal, la cual constituye no simplemente una nueva forma de hacer las cosas, sino una nueva manera de impartir Justicia penal, con las implicaciones estructurales y, quizás de mayor importancia, de cambio de actitudes y mentalidades que, tanto en los operadores como en los mismos ciudadanos, ello conlleva; es necesario abordar su diagnóstico desde tres interrogantes básicas: ¿Era necesaria la reforma?, ¿Qué es, en definitiva, lo que ofrece la reforma? $y$, finalmente, ¿Hacia donde pretendemos ir con la reforma?
\end{abstract}

En otras palabras, resulta debido analizar la reforma desde una correcta perspectiva en cuanto a su utilidad instrumental como herramienta de una, desgraciadamente en nuestro país, no siempre consciente y orientada política criminal ${ }^{2}$.

Para ello, y siguiendo la metodología propuesta de dar concreta respuesta a las interrogantes anteriormente planteadas; debemos, en primer lugar, justificar la reforma

\footnotetext{
1 El presente artículo tiene como base la conferencia "La reforma procesal penal en Honduras: Un encuadre general", impartida por el Dr. Cuéllar en el Colegio de Abogados de Honduras, el 25 de junio de 2002, en ocasión de la presentación de la segunda edición de su libro "La reforma procesal penal y el Ministerio Público en Honduras: Justificación y perspectivas", editado por el Instituto de Estudios Comparados en Ciencias Penales y Sociales de Honduras (INECIPH).

2 Debiendo entenderse por política criminal, junto con Delmas Marry, y en su sentido más amplio y general, "el conjunto de métodos por los que el cuerpo social organiza la respuesta al fenómeno criminal". Delmas Marty, Mireille, Les grands systémes de politique criminelle, Presses Universitaires de France, París, Francia, 1992, Pág. 13. O, como más específicamente dentro del ámbito penal la define Binder: "Conjunto de decisiones, instrumentos y reglas que orientan el ejercicio de la violencia estatal (coerción penal) hacia determinados objetivos". Binder, Alberto, Diez preguntas básicas sobre política criminal, en la revista jurídica de INECIPH "Justicia y Poder", volumen 1, número 1, Pág. 40.
} 
misma, para, desde ese punto de partida y en segundo lugar, proceder a describir cuales son sus innovaciones principales, $y$, sobre todo, que beneficios prácticos reporta. Finalmente, en tercer lugar y abordado lo anterior, intentaremos ubicar el nuevo sistema procesal penal dentro del contexto de una política criminal coherente que, desde este estrado, nos permitimos sugerir como posible respuesta al fenómeno criminal que actualmente lesiona las fibras más sensibles de nuestra estructura social, al ponerse en riesgo eminente nuestra propia convivencia diaria y que, a nuestro parecer, a fomentado un sinnúmero de irreflexivas reacciones legislativas y de orden gubernativo, que lejos de contribuir a un eficaz enfrentamiento a la delincuencia, ha disipado esfuerzos y se ha constituido en verdadero obstáculo para la implementación de una verdadera lucha interinstitucional y ciudadana coincidente, $y$ a nuestro parecer lo más grave, ha venido a significar la restricción de derechos y garantías individuales, bajo el erróneo entendido de que éstas son algo completamente distinto al pretendido concepto de "seguridad ciudadana".

Entiéndasenos bien, nuestro objetivo, como siempre ha sido $^{3}$, no es el de criticar de forma irresponsable por el simple acto de criticar, si no el de realizar una crítica "constructiva", y nunca "destructiva", procurando someter a consideración planteamientos serios y viables de solución, para intentar dar mejor respuesta a un problema que nos atañe a todos, y del cual, a nuestro criterio, nadie que tenga algo que aportar debe quedar al margen. He aquí nuestra pequeña contribución.

\section{Justificación de la Reforma en Honduras}

La necesidad de reforma del antiguo sistema procedimental penal, establecido y regulado por el Código de Procedimientos Penales de 1984 y aún vigente para las causas iniciadas antes de la total entrada en vigencia del nuevo Código Procesal Penal, en febrero del 2002; se pone de manifiesto ante su demostrada incapacidad de superar dos pruebas elementales, pero ciertamente relevantes para un Estado democrático de Derecho, como pretende ser el hondureño (Art. 1 de la $\mathrm{CH}$ ): La constitucional ${ }^{4}$ y la operativo funcional, es decir, como instrumento eficaz de política criminal.

\section{a) Desde la Perspectiva Constitucional}

Con el objeto de efectuar una aproximación responsable al tema, resulta necesario destacar, en primer lugar, que el sistema jurídico democrático hondureño diseñado por nuestros constitucionalistas, no fue el de un simple Estado de Derecho, sino el de un Estado Constitucional de Derecho, donde su nota característica primordial

3 Cuéllar Cruz, Rigoberto, La reforma procesal penal y el Ministerio Público en Honduras: Justificación y perspectivas (segunda edición actualizada y ampliada), Instituto de Estudios Comparados en Ciencias Penales y Sociales de Honduras (INECIPH), Tegucigalpa, Honduras, 2002, Pág. 19.

4 Con respecto a los extremos de inconstitucionalidad de todo el sistema procedimental penal de 1984, puede verse un estudio a fondo en Cuéllar Cruz, Rigoberto, La reforma procesal penal y el Ministerio Público en Honduras..., cit., Págs. 99-138. 
deja de ser la de "el imperio de la Ley" y es sustituido por el de "el imperio de la Constitución", es decir, se supera el principio de legalidad como nota definitoria, por el principio de constitucionalidad. En palabras de Pérez Royos, la Constitución se erige de esta forma en "el punto de referencia de la Ley. La Ley, en el punto de referencia de todo lo demás".

Y cabe insistir en que la diferencia no es solo semántica, sino que en su aceptación esta en juego el obligado reconocimiento de la norma constitucional como norma jurídica directamente aplicable. Dando por superada así, la concepción romántica de la normativa constitucional como simple norma marco, necesitada de normativa ordinaria para su debido desarrollo y efectividad.

Por consiguiente, se deduce que nuestra Constitución se erige, no sólo en la primera de las fuentes de nuestro Derecho, sino que se convierte en la norma que regula e informa, de manera necesaria y obligatoria, las demás fuentes del derecho que conforman nuestro ordenamiento jurídico ${ }^{6}$.

La comprobación del Estado hondureño como auténtico Estado Constitucional de Derecho, y por ende el obligado respeto a todas las exigencias expuestas que de ello se derivan, resulta fácilmente deducible de un somero repaso a nuestra propia normativa constitucional ${ }^{7}$. Así, por ejemplo, la atribución otorgada a la Corte Suprema de Justicia para conocer, además de los recursos de casación, revisión y amparo, de los recursos de inconstitucionalidad de las leyes (Art. 313, numeral 6, CH); la obligación dirigida a Jueces y Magistrados de, en casos de incompatibilidad entre una norma constitucional y una legal ordinaria, aplicar la primera (Art. $320 \mathrm{CH})^{8}$; así como normas de alto fervor constitucionalista que incluso llaman a la insurrección popular, como obligación más que como derecho, en casos de violación del orden constitucional establecido (Arts. 3 y $375 \mathrm{CH}$ ). Ya en el orden procesal penal, dicho reconocimiento deviene especialmente evidente a partir del nuevo motivo de casación por infracción de precepto constitucional (Art. $361 \mathrm{CPPH}$ ).

Expuesto lo anterior, y evidenciada la especial vinculación que debe prevalecer entre la normativa procesal penal (como norma ordinaria) y la norma constitucional, en la cual la primera deberá guardar un absoluto y obligado respeto hacia la segunda; a fin de constatar si el Código de Procedimientos Penales de 1984 supera la prueba de constitucionalidad, bastará con analizar si el mismo cumple con las exigencias constitucionales mínimas consagradas sobre la materia. Teniendo que llegar a la

5 Pérez Royo, Javier, Curso de derecho Constitucional, Marcial Pons, Ediciones Jurídicas, S.A., Madrid, España, 1995, Pág. 99.

" Cuéllar Cruz, Rigoberto, La Reforma Procesal Penal y el Ministerio Público en Honduras.., cit., Pág. 29.

7 Cuéllar Cruz, Rigoberto, La reforma procesal penal y el Ministerio Público en Honduras..., cit., Págs. 26-29.

8 Norma cuyo contenido, en cuanto a un aparente reconocimiento a favor de un control jurisdiccional de carácter difuso de la constitucionalidad ordinaria, puede resultar argumentable, pero cuya intención de prevalencia de la norma constitucional es, por sí sola, indiscutible. 
conclusión que dicha normativa procedimental, no sólo resulta incoherente con los derechos y garantías fundamentales más elementales, sino aún más, resulta frontalmente contradictoria con las mismas.

Así, a manera de ejemplos ilustrativos importantes y sin ánimo de ser exhaustivos, la forma misma de dar inicio al procedimiento penal, mediante acusación formulada ante un Juez quien tenía atribuida a la vez la función investigadora, situaba en serio precario el propio derecho al estado de inocencia (Art. $89 \mathrm{CH}$ ) de cualquiera que se viese sometido a procedimiento, al forzar al órgano persecutor oficial (Ministerio Público) a tener que acusar antes de investigar. Con lo cual, de hecho, la persona era considerada de entrada como culpable mientras no se demostrara su inocencia a lo largo del procedimiento ya instaurado.

Asimismo, los derechos de defensa y contradicción no eran más que simples enunciados sin ninguna incidencia o efectividad real, prueba de lo anterior es que el momento procesal en que el Juez venía legalmente obligado a proveer al imputado con asistencia técnica, de oficio de ser necesaria, era hasta en etapa de plenario al momento de contestar la formalización de acusación. Si a lo anterior agregamos el hecho, poco argumentable, que el verdadero juicio en el procedimiento anterior se libraba en la decisión sobre el auto de prisión en etapa de sumario ${ }^{9}$, llegaremos fácilmente a la conclusión que lo que existía era un estado absoluto de indefensión.

Por otra parte, el Derecho fundamental a un Juez imparcial era igualmente de imposible concreción en un sistema en el cual el mismo Juez que conocía de la etapa de sumario, se pronunciaba posteriormente en etapa de enjuiciamiento. Con lo cual, por un lado, el mismo sujeto procesal a quien se encomendaba la función instructora legitimaba sus propios actos de investigación, y, por otro, ello significaba que el imputado se enfrentaba, no sólo a la parte acusadora, sino también a quién, en principio y según mandato constitucional, debía servir como tercero imparcial.

Finalmente, la prisión preventiva como regla de observancia general, atentaba abiertamente contra el derecho fundamental a la libertad. Debiendo añadir, que la decisión entre dicha medida cautelar personal y la única otra alterna consistente en la fianza, no constituía una verdadera decisión de carácter jurisdiccional, pues bastaba con saber contar del uno al cinco para determinar que, si la pena abstracta máxima sobrepasaba los cinco años, debía decretarse, de forma automática y sin lugar a discreción judicial alguna, la prisión preventiva, $y$, siempre que no se excediera de dicho límite, procedía la fianza ${ }^{10}$.

9 Con respecto al auto de prisión en el viejo procedimiento y el significado y alcance del auto de prisión en el nuevo proceso penal, resulta interesante el estudio efectuado por la Fiscalía General, a través del dictamen del Departamento de Capacitación y Asesoría Técnico Jurídica, número DCATJ-002-2002.

11 Un estudio comparativo de la prisión preventiva y la regulación de la misma en el viejo y en el nuevo proceso penal, puede verse en Cuéllar Cruz, Rigoberto, con Caballero Klink, Jesús, y Galán Miguel, Juan Antonio, Las medidas cautelares, "Cuadernos de Estudios Judiciales Rafael Alvarado Manzano", número 8, Corte Suprema de Justicia-Agencia Española de Cooperación Internacional, Tegucigalpa, Honduras, 2001. 


\section{b) Desde la Perspectiva Operativo Funcional}

Analizado en su contexto constitucional, lo cierto es que el antiguo procedimiento penal tampoco cumplió con su función de instrumento eficaz contra el delito.

En términos generales, se trataba de un sistema escrito promotor de actitudes burocráticas, extremadamente lento, y por ello, no sólo violatorio de derechos fundamentales, sino claramente ineficaz al incumplir con su función preventiva, a través de la imposición de sanciones ejemplificantes que requieren de cierto grado de inmediatez entre la comisión del hecho y la imposición de la correspondiente pena.

Aunado a lo anterior, y también como consecuencia del principio procedimental de la escritura denunciado, igualmente se trataba de un sistema carente de transparencia que auxilió a provocar un desgaste de la confianza en las actuaciones de los operadores de justicia, entre éstos, especialmente del Poder Judicial.

Por otra parte, demostró ser un sistema altamente selectivo, hasta cierto punto eficiente en la persecución de la pequeña criminalidad y contra los sectores sociales más desproveídos, pero absolutamente ineficaz en cuanto a la persecución de delitos cometidos por la delincuencia organizada o actos de corrupción, denominados comúnmente delitos de "cuello blanco", verdaderos flagelos de nuestras sociedades latinoamericanas modernas.

Finalmente, y en relación estrecha con lo anterior, se trataba de un sistema de enjuiciamiento que no permitía un trato diferenciado de causas, negando así cualquier intento de priorización formal de delitos, obligando a invertir igual cantidad de recursos materiales y personales en delitos de menor impacto social, que en aquellos que, en atención al mayor relieve de los bienes jurídicos protegidos, eran merecedores de atención especializada. Como resultado constatable de este inútil esfuerzo por tratar igual lo desigual, se desatendían tanto unos como otros, y se congestionaba innecesariamente el sistema judicial con causas que hubiesen recibido mejor tratamiento mediante otras vías alternas de composición social" ${ }^{\prime \prime}$.

\footnotetext{
"Ahora bien, cabe evidenciar que la denunciada falta de mecanismos en el antiguo procedimiento que permitiesen una necesaria priorización de causas, era cierta desde un punto de vista formal-legal, ya que, en la práctica, dicha priorización sí tenía lugar, si bien al margen de parámetros legalmente establecidos y en perjuicio del derecho a la tutela judicial efectiva.

Así, la denuncia de un ciudadano debía sobreponerse a una serie de obstáculos que descriptivamente consistían en lo siguiente: Una vez interpuesta la denuncia en sede policial, éste le daba trámite investigativo de conformidad a la prioridad que dicho órgano estimase para la misma; en su caso, superada esta primera etapa, la denuncia debía superar la priorización efectuada por el Ministerio Público, normalmente y si el hecho era considerado como menos grave a criterio del Fiscal asignado al expediente, éste lo archivaba en espera de que el ofendido se personará en su despacho y exteriorizará nuevamente su voluntad de dar consecución a la causa; presentada la acusación, aún restaba la priorización informal por parte de órgano judicial, quien, igualmente en atención a la gravedad del hecho o a su mayor o menor impacto social, engavetaba la causa, la cual, en el mejor de los casos, llegaba hasta el auto de prisión, ya sea que ello llevará implícito la imposición de una prisión preventiva o la constitución de una fianza, y ahí estaba condenada a permanecer dormida durante años.
} 


\section{Alternativas propuestas por el nuevo Código Procesal Penal}

Señaladas las deficiencias del antiguo sistema procedimental penal, tanto en el ámbito constitucional como en el ámbito funcional operativo, llegó el momento de examinar cuál es la propuesta que efectúa la nueva normativa procesal penal para superar las mismas.

Adelantando, que el problema se reconduce al conflicto que debe enfrentar cualquier sistema procesal penal moderno, al intentar equilibrar responsablemente entre los dos valores que conforman sus objetivos y polos, por una parte, en el obligado respeto a derechos y garantías individuales, y, por otro, en la eficaz persecución del delito.

Para ello, reconduciremos el tema al análisis de las que constituyen, en nuestra opinión, las principales innovaciones contenidas en el Código.

\section{a) Manifestaciones del Principio de Oportunidad}

Debe entenderse por principio de oportunidad, a la luz de la normativa procesal penal hondureña, aquél que confiere facultad al Ministerio Público para que, en atención a determinados supuestos legalmente previstos (principio de oportunidad reglada), relacionados con el hecho mismo, con las personas que lo cometen o la relación de éstas con otros sujetos o hechos, pueda condicionar o abstenerse de ejercitar la acción penal pública con respecto a la comisión de actos de naturaleza penal y en los cuales el autor se imputa como posible culpable ${ }^{12}$. Así, en el nuevo Código Procesal Penal, se establecen como manifestaciones del mismo, los siguientes: Los criterios de oportunidad (Art. $28 \mathrm{CPP}$ ), la conformidad del procedimiento abreviado (Arts. 403 y 404), la estricta conformidad del proceso ordinario (Art. 322 CPP) y la suspensión condicional del proceso penal (Arts. 36-40 CPP).

Sin ánimo de profundizar sobre un tema ciertamente complicado y doctrinalmente discutido, sobre todo con respecto a la justificación de su vigencia en el proceso penal ${ }^{13}$, lo que ciertamente excedería por mucho el objetivo del presente trabajo; nos limitaremos a enunciar, resumidamente, las principales ventajas inherentes a la puesta en vigencia en

12 Cuéllar Cruz, Rigoberto, La reforma procesal penal y el Ministerio Público en Honduras..., cit., Pág. 357. IDEM, por el mismo autor, en Los criterios de oportunidad en el proceso penal: La experiencia hondureña en el marco de su vigencia anticipada al nuevo Código Procesal Penal, revista jurídica de la Unidad Técnica de Reforma Penal de la Corte Suprema de Justicia, "Justicia Penal", Año1, número 1, enero de 2002, Pág. 126.

13 Con respecto a la verificación de una Justicia material, por encima de una Justicia formal, como justificación de la vigencia del principio de oportunidad en Latinoamérica, puede verse, especialmente, Cuéllar Cruz, Rigoberto, La reforma procesal penal y el Ministerio Público en Honduras..., cit., Págs. 357 y ss; así mismo, y por el mismo autor, Los criterios de oportunidad en el proceso penal..., cit., Págs. 125 y ss; igualmente, puede verse la doctrina de Fiscalía General al respecto, en los dictámenes del Departamento de Capacitación y Asesoría Técnico-Jurídica, números DCATJ-001-2000; DCATJ-004-2000; DCATJ001-2001; DCATJ-002-2001; DCATJ-005-2001; DCATJ-010-2001 y DCATJ-017-2001, así como los instructivos 1-2001, sobre el criterio de oportunidad, y 2-2001, sobre el procedimiento abreviado. 
nuestro nuevo proceso penal de manifestaciones del principio de oportunidad, entendiendo que las mismas se derivan de una demostrada necesidad de flexibilizar el principio de legalidad estricta ${ }^{14}$, vigente en nuestro antiguo procedimiento penal.

Así, y desde el punto de vista constitucional, a través de los mismos se efectiviza de mejor manera el ejercicio del derecho fundamental a la libertad, al permitir vías alternas al proceso y, por ende, a la imposición de penas privativas de libertad, muchas veces innecesarias o desproporcionadas.

En la misma línea de lo anterior, por su medio se permite una mejor adecuación a las finalidades que constitucionalmente se le reconocen hoy a la pena, a parte de la meramente retributiva; permitiendo, por medio del arrepentimiento y el interés resarcitorio del daño causado por parte del imputado, un mejor cumplimiento de las funciones de prevención general y especial, así como la pronta reparación del daño a favor de los derechos de la víctima, como nueva finalidad constitucionalmente legítima de la sanción penal.

Desde el punto de vista de decisión de política criminal, permite crear válvulas legales de escape para causas de menor entidad que admiten fórmulas de simplificación procesal que van desde evitar el inicio del proceso (criterios de oportunidad), hasta el acortamiento anormal del mismo (suspensión condicional y conformidades); lo que, a su vez, propicia un uso más racional de medios a través de una priorización de causas, permitiendo una atención más especializada a delitos que, por su propia naturaleza o connotación, lo merecen (como ser, delitos de crimen organizado, casos de corrupción, delitos informáticos, delitos financieros, etc.), a la vez que otorgan una respuesta efectiva y rápida a causas que reciben un mejor tratamiento, a favor tanto de imputado como de víctima, a través de estas salidas alternas al enjuiciamiento, favoreciendo, a su vez, una economía procesal que se refleja constatablemente en un notable descongestionamiento del sistema judicial.

En el ámbito de una política carcelaria humana y racional, la aplicación de medidas desjudicializadoras, especialmente tendentes a beneficiar a infractores primarios, permite una mejor rehabilitación del delincuente al evitarse, aunque ello resulte en principio contradictorio, la cruda realidad de nuestros centros penitenciarios; los cuales, lejos de promover una efectiva resocialización del recluso, producen efectos criminógenos y de estigma social absolutamente contrarios a las finalidades

14 Al respecto puede verse, entre otros, Tijerino Pacheco, José María, El principio de oportunidad en el ejercicio de la acción penal, en "Reflexiones Sobre el Nuevo Proceso Penal", Imprenta y Litografía Mundo Gráfico, S.A., San José, Costa Rica, 1996, Págs. 87-104; Armenta Deu, Teresa, Criminalidad de bagatela y principio de oportunidad: Alemania y España, Promociones y Publicaciones Universitarias, Barcelona, España, 1991; Barona Vilar, Silvia, La conformidad en el proceso penal, editorial Tirant lo Blanch, Valencia, España, 1994; Botron Baliña, Pedro M., La conformidad en el proceso penal, editorial McGraw Hill, Madrid, España, 1998; Cabezudo Rodríguez, Nicolás, El sistema de justicia penal negociada en los Estados Unidos de Norte América, editorial Comares, Granada, España, 1996; y, De Diego Diez, Luis Alfredo, Justicia criminal consensuada (algunos modelos del derecho comparado en los EE.UU., Italia y Portugal), editorial Tirant lo Blanch, Valencia, España, 1999. 
educacionales que hipócrita o ilusamente se pretenden obtener. A su vez, y por si lo anterior no fuese razón suficiente, se descongestionan los centros de reclusión, que en la actualidad albergan poblaciones muy por encima de su capacidad materialls.

\section{b) La Instrucción por el Ministerio Público}

La superación de la figura procesal del Juez Instructor por la del Fiscal Instructor, además de consolidar el principio acusatorio como principio informador del nuevo sistema procesal penal ${ }^{16}$, permite, desde la óptica constitucional, garantizar estructuralmente la obligada imparcialidad objetiva del órgano jurisdiccional; lo cual, consecuentemente y al asumir el Juez su legítima posición como tercero supra parte, refuerza el derecho de defensa de las partes, al reconocer de mejor forma el principio de contradicción en un ideal estadio de igualdad.

Por otra parte, se respeta con mayor amplitud el estado de inocencia del imputado, al reconocerse una nítida distinción entre la etapa de instrucción, constituida por meros actos de investigación, y una auténtica etapa de enjuiciamiento, constituida por una audiencia oral y pública donde se desarrolla, previa contradicción, el único elemento probatorio a ser valorado en la sentencia. Con lo cual, nada de lo realizado por el Ministerio Público antes del juicio oral, adquiere, per se, valor probatorio alguno ${ }^{17}$. Eliminándose así la posibilidad de sentencias anticipadas, como ocurría con el visto auto de prisión, regulado en el antiguo Código de Procedimientos Penales ${ }^{18}$. Circunstancia que se refuerza, a favor del derecho fundamental a la libertad, al concebirse la prisión preventiva como medida cautelar personal de carácter excepcional y, en todo caso, como una más dentro del abanico de opciones previstas en el nuevo Código (Artículo $173 \mathrm{CPP})^{19}$.

Desde el punto de vista operativo funcional, presenta las ventajas de una etapa de instrucción dinámica y ágil en manos de órganos administrativos (policial y Fiscal), $y$, por ende, liberada de las solemnidades y formalidades intrínsecas a cualquier etapa judicializada. De esta forma, sólo se incorpora a proceso aquellos elementos de investigación conducentes al hecho denunciado.

15 Una visión crítica y realista sobre los centros penitenciarios en América Latina, puede verse en Tocora, Fernando, Política criminal en América Latina, Ediciones Librería del Profesional, Bogotá, Colombia, 1990, Págs. 79 y ss.

16. Con respecto al Fiscal Instructor como corolario de las exigencias derivadas del principio acusatorio, puede verse Cuéllar Cruz, Rigoberto, La reforma procesal penal y el Ministerio Público..., cit., Págs. 305 y ss.

17 Salvo los casos excepcionales de prueba anticipada, en los cuales, no obstante, se respetan en su total amplitud los derechos de defensa y contradicción en plano de igualdad y ante órgano jurisdiccional competente (Art. 277 CPP).

1* Si bien, la debida comprensión de lo anterior aún representa uno de los principales retos a superar en la realidad práctica del nuevo sistema, ante el temor fundado que se desnaturalice la audiencia inicial en juicios orales anticipados, al persistir, por desgracia y en razón de la subsistente referencia constitucional, el auto de prisión, ya sin razón de ser en el nuevo proceso penal. Al respecto, puede verse un estudio en el dictamen del Departamento de Capacitación y Asesoría Técnico-Jurídica de Fiscalía General, número DCATJ-0022002.

19 Sobre el tema puede verse, especialmente, Cuéllar Cruz, Rigoberto, con Caballero Klink, Jesús, y Galán Miguel, Juan Antonio, Las Medidas..., cit., Págs. 1-16. 
Desjudicialización de la etapa de instrucción que a dado lugar, desmintiendo cualquier comentario malintencionado o infundado, a una mayor eficiencia en la investigación de los delitos, al otorgar facultades limitativas de derechos y garantías, antes vedadas y exclusivas del órgano judicial, a los entes policiales y fiscales; sin que ello se traduzca automáticamente en violación de derechos individuales, pues, en todo caso, y mediante la necesaria convalidación judicial inmediata del acto investigativo, siempre se salvaguarda el obligado principio de jurisdiccionalidad, si bien a través de un control judicial posterior ${ }^{20}$.

No menos importante, y sobre todo en un país de recursos limitados como ciertamente lo es el nuestro, igualmente se delimitan claramente competencias funcionales entre los distintos órganos encargados de la persecución penal (el policía investiga, el Fiscal dirige, desde un punto de vista técnico jurídico, la investigación y sostiene la pretensión acusatoria hasta sentencia; $y$, el Juez, en etapas previas al juicio vigila por el respeto de derechos y garantías, y, en etapa de enjuiciamiento, juzga y hace ejecutar lo juzgado), evitando con ello la innecesaria duplicidad de dichas funciones, especialmente importante en la etapa de investigación ${ }^{21}$.

\section{c) El Principio Procedimental de la Oralidad}

Sin lugar a dudas, el elemento más llamativo, por aparente, de la reforma procesal penal, es la superación del antiguo procedimiento predominantemente escrito, por la preeminencia, en el nuevo, del principio procedimental de la oralidad, especialmente reflejado en su etapá de enjuiciamiento: La audiencia de debate público.

Desde el punto de vista constitucional, a través del mismo se efectiviza la plena vigencia de derechos fundamentales tan relevantes como el de defensa, y ello, al potenciar al máximo derechos instrumentales los de contradicción, audiencia e inmediación.

No obstante, y sin restar la indiscutible importancia de lo aseverado anteriormente, es desde la perspectiva de la oralidad como parte integral del nuevo sistema de enjuiciamiento criminal al servicio de la política criminal, donde se reflejan, a nuestro parecer, sus virtudes más interesantes.

Así, por medio de la oralidad se obtiene, en primer lugar, una evidente desburocratización del sistema de Justicia penal, pues en razón de la misma, la forma

20 Así, por ejemplo, la detención preventiva y la aprehensión, sin orden de captura judicial previa (Arts. 175 y $176 \mathrm{CPP}$ ); el allanamiento de morada (Art. $212 \mathrm{CPP}$ ); interceptación de comunicaciones (Art. 221 CPP); $y$, las intervenciones corporales (Art. 107 CPP).

21 Al respecto, cabe recordar que, previo a la total entrada en vigencia del nuevo Código Procesal Penal, se encontraban forzados a co existir, por una parte, un Código de Procedimientos penales que atribuía la función investigativa al Juez; $y$, por otra, una Ley del Ministerio Público que regulaba la función de investigar los ilícitos penales como responsabilidad del Fiscal. Lo cual conducía en la práctica al absurdo de dos esfuerzos de investigación, teniendo que repetirse por parte del Juez, dentro del proceso penal, la investigación llevada a cabo por el Fiscal en sede administrativa. Sobre el tema puede verse el dictamen elaborado por el Departamento de Capacitación y Asesoría Técnico-Jurídica de Fiscalía General, número DCATJ-012-2001. 
excesiva, es decir el innecesario formalismo que en muchas ocasiones atenta frontalmente contra una tutela judicial efectiva ${ }^{22}$, pierde prevalencia sobre el derecho de fondo. Es decir, el "qué se dice" recupera su lugar de prioridad sobre el "cómo se dice". Extremo que fácilmente puede constatarse de un somero examen a la regulación que, sobre el régimen de nulidades, efectúa la nueva norma procesal penal, en la cual la subsanación de actos no esenciales constituye regla general ${ }^{23}$. Consecuencia directa de lo anterior: Un sistema mucho más dinámico y eficaz de enjuiciamiento, lo que permite, a su vez, una respuesta más inmediata del conflicto penal sometido a tratamiento, ante los ojos de la comunidad.

En segundo lugar, se garantiza una mayor confianza por parte de la sociedad hacia los propios operadores de Justicia, necesaria en tiempos como los presentes donde la incredulidad hacia las instituciones públicas, especialmente de aquéllas vinculadas con la Administración de Justicia, lamentablemente se exterioriza como generalizada. Y ello, por vía de la transparencia que la oralidad promociona en los actos a realizar ante el órgano jurisdiccional, superándose las corruptelas que se facilitaban con el anterior sistema predominantemente escrito y secreto.

Finalmente, y como valor añadido a los positivos aspectos anteriores, se produce lo que denominamos una sana y necesaria democratización del sistema de Justicia penal, al permitirse, especialmente en la etapa de juicio oral y público, un control por parte de la ciudadanía en cuyo nombre se administra Justicia, si bien ciertamente limitado a una supervisión como espectador calificado crítico, sin intervención directa en la misma, como sí ocurre en sistemas procésales de nuestro entorno próximo como Nicaragua y El Salvador, donde se ha instaurado la figura del Tribunal por Jurado, sin que ello reste en lo absoluto a la calificación de nuestro sistema procesal penal como acusatorio.

\section{Situación Actual de la Reforma Procesal Penal: Logros y Retos}

Vistas las propuestas principales que ofrece el nuevo Código Procesal Penal para enfrentar de mejor forma las carencias evidenciadas por el antiguo sistema, desde sus ámbitos tanto constitucional como funcional operativo; resulta conducente ahora examinar si sus planteamientos, desde el punto de vista teórico, han merecido resultados objetivamente comprobables desde el punto de vista práctico, es decir, sí, a poco más de diez meses de vigencia de la nueva norma adjetiva, se han obtenido resultados positivos que nos conduzcan a ser optimistas con respecto al efectivo

\footnotetext{
22 Al respecto, un interesante análisis en cuanto a las diferencias existentes entre "forma" $y$ "formalismo" y como éste último puede restar eficacia al cumplimiento de una tutela judicial efectiva, puede verse en el dictamen del Departamento de Capacitación y Asesoría Técnico-Jurídica de Fiscalía General, número DCATJ-003-2002.
}

23 Artículos 165 al 171 del Código Procesal Penal. 
cumplimiento de las metas ya planteadas y descritas, por supuesto, no esperando más de lo que la misma puede materialmente llegar a ofrecer ${ }^{24}$.

\section{a) Logros}

De entrada, podemos sostener con orgullo que la nueva fórmula de administrar Justicia penal en Honduras, reflejada en su nueva normativa procesal penal y a pesar de su muy reciente puesta en vigencia, funciona.

Ejemplos importantes del éxito parcial obtenido son, entre otros, el hecho de que a diez meses de su total vigencia se han celebrado ya, en todo el territorio nacional, más de 100 juicios orales ${ }^{25}$. Estadística ciertamente sorprendente, sobre todo si tomamos en consideración el tiempo que tomo a países vecinos, como Guatemala y El Salvador, el llegar a realizar su primera audiencia pública de debate.

Por otra parte, resulta importante destacar que el promedio de tiempo transcurrido en las causas anteriormente referidas, desde la presentación del respectivo requerimiento Fiscal hasta su culminación por sentencia en juicio oral y público, fue de un promedio de entre tres y cuatro meses. Con lo cual se ha reducido dramáticamente el promedio de duración de causas que fomentaba el anterior sistema procedimental, que oscilaba entre los cinco y seis años.

Asimismo, la concepción que de la prisión preventiva efectúa la nueva norma, como excepción dentro del enorme abanico de medidas cautelares personales previstas, y en contraste con su naturaleza de regla general obligada, tal y como venía siendo concebida por su regulación en el antiguo Código de Procedimientos Penales de 1984, se esta cumpliendo.

Así, cabe señalar que, hasta el mes de junio de 2002, del total de medidas cautelares solicitadas por el Ministerio Público ante el órgano jurisdiccional en los distintos procesos incoados (un total de 2,432); sólo en 438 se estimó la necesidad de la prisión preventiva, significando el $29 \%$ del total de medidas impuestas y una remisión a los centros penales del país de un 30\% de las personas procesadas, difiriendo significativamente del casi $100 \%$ de procesados remitidos por el anterior procedimiento penal ${ }^{26}$.

24 Sobre la anterior afirmación, es importante evidenciar que no resultaría, ni lógico ni posible, esperar que la reforma procesal penal, por sí sola, pueda llegar a dar respuesta, por ejemplo, al fenómeno criminal en alza que actualmente amenaza la normal convivencia en nuestro país, albergando la ilusa esperanza de que se trata de una especie de pilldora mágica capaz de erradicar la delincuencia; y, en cierta forma, eso es uno de los extremos que deseamos clarificar desde el presente trabajo, al dar un tratamiento al nuevo Código Procesal Penal como una pieza más, sin duda de las más importantes pero no la única, para crear una política criminal coherente que de respuesta efectiva, pero sobre todo definida, al enorme problema referido.

25 Dato estadístico proporcionado por la Unidad Técnica de Reforma Penal del Ministerio Público y comprendido desde el mes de marzo hasta el mes de noviembre de 2002.

${ }^{26}$ Informe Estadístico del Nuevo Proceso Penal (Período Marzo-Junio de 2002), elaborado por la Unidad Técnica de Reforma Penal del Ministerio Público. 
Con lo cual, y ante un inobjetable $71 \%$ de medidas sustitutivas impuestas, y con muy raras excepciones de inobservancia a las mismas, podemos sostener que en Honduras, poco a poco, vamos quebrantando la cultura carcelaria que hasta recientemente prevalecía en nuestra realidad jurídica. Entendiendo la ciudadanía en general, por una parte, que la prisión preventiva no debe comprenderse como pena anticipada en clara violación del estado constitucional de inocencia; y, por otra, que el someterse voluntariamente a enjuiciamiento auxilia, lejos de perjudicar, sus pretensiones como imputado orientadas a una pronta resolución del conflicto.

Finalmente, y con respecto a la aplicación de medidas simplificadoras alternas al enjuiciamiento, hasta el mes de junio de 2002 se habían aplicado un total de 1,459 medidas a nivel nacional, comprendiendo entre éstas, mayoritariamente, la aplicación de criterios de oportunidad y procedimientos abreviados ${ }^{27}$; datos estadísticos que reflejan, objetivamente, una aplicación generalizada de las distintas manifestaciones del principio de oportunidad, con las consecuencias positivas prácticas ya discutidas a que el mismo tiende, principalmente, el descongestionamiento del sistema judicial y el uso racional de recursos por los entes persecutores estatales. Pero, igualmente interesante resulta el analizar los beneficios que la estimación de estos instrumentos de simplificación han significado para las víctimas; desprendiéndose que, como resultado directo de esas 1,459 medidas alternas aplicadas, se obtuvo un total de 4, 242, 929.98 Lempiras, en concepto de indemnización ${ }^{28}$. Indicando dicho dato, una respuesta igualmente efectiva a favor del legítimo interés resarcitorio de éstas.

Descritos los enormes logros parciales obtenidos hasta la fecha, cabe preguntarse que elementos y decisiones han propiciado los mismos. Tema que, por otra parte, resultará de posible interés a países que hasta muy recientemente se han incorporado a reformas legislativas procesales de muy similares, sino idénticas características, y, por tanto, destinados a sufrir igualmente una difícil, pero ciertamente gratificante, etapa de transición; como es el caso particular, por ejemplo, de Nicaragua.

A nuestro criterio, tres son resumidamente las circunstancias que han propiciado los logros parciales examinados y que han incidido decisivamente en el desarrollo de una etapa de transición esperanzadora ${ }^{29}$.

27 Informe Estadístico del Nuevo Proceso Penal (Período Marzo-Junio de 2002), elaborado por la Unidad Técnica de Reforma Penal del Ministerio Público.

28 Informe Estadístico del Nuevo Proceso Penal (Período Marzo-Junio de 2002), elaborado por la Unidad Técnica de Reforma Penal del Ministerio Público.

2y A las que habrá necesariamente que agregar, tanto la entrada en vigencia en 1994 de una Ley del Ministerio Público concebida para un sistema acusatorio, la cuál fue induciendo un anticipado cambio de mentalidad en los Fiscales, quienes fueron asumiendo su rol protagónico como directores de la investigación a pesar de las serias limitaciones que ello representaba dentro del antiguo sistema para entonces aún vigente, informado, paralelamente, por la figura del Juez Instructor; como la precavida elaboración de un plan general de transición, en el cuál se previeron todas las necesidades, de carácter logístico y material, que debían ser atendidas para la efectiva entrada en vigencia del nuevo Código Procesal Penal. Plan cuya ejecución hoy se encuentra encargada a Unidades Técnicas de Reforma, existente tanto en el Poder Judicial, como en el Ministerio Público. 
Así, en primer lugar, los valiosos esfuerzos que todas las instituciones del sector Justicia, especialmente el Poder Judicial, a través de su Escuela Judicial, y el Ministerio Público, a través de su Departamento de Capacitación y Asesoría Técnico-Jurídica, han invertido en materia de capacitación. Mismas que tuvieron su más importante concreción con la ejecución del ambicioso proyecto de capacitación conjunta desarrollado durante el transcurso del año anterior a la entrada en vigencia del nuevo Código Procesal Penal, y que involucró la formación de Jueces, Fiscales, Policías, Defensores Públicos, e incluso de algunos procuradores en el ejercicio privado, a nivel nacional.

Proyecto que propició, no sólo una necesaria y adecuada formación científica con respecto a la nueva normativa y sus innovaciones, sino igualmente el valor agregado de posibilitar el consenso de pareceres, así como el valioso acercamiento entre los diferentes actores del nuevo sistema, extremo que indiscutiblemente facilitó la posterior coordinación y colaboración entre los mismos en beneficio de la eficacia del propio sistema.

En segundo lugar, y complementariamente, la debida atención prestada en el ámbito de asesoría técnica. Lo anterior, mediante la creación de unidades especializadas de respuesta inmediata a las interrogantes que gradualmente se han ido presentado desde la aplicación práctica del nuevo sistema procesal penal.

Al respecto, especial atención merece la creación, como dependencia directa del Fiscal General de la República, del Departamento de Capacitación y Asesoría Técnico-Jurídica del Ministerio Público ${ }^{30}$; órgano que ha demostrado, a pesar de su reciente creación en octubre del año 2000, constituir una de las piezas claves para garantizar una exitosa transición del viejo al nuevo sistema procesal, sobre todo, y en cuanto a su función de asesoría técnica se refiere, a través de sus funciones específicas de elaborar dictámenes con relación a contestación escrita de consultas de toda índole (procesal, penal, constitucional, etc.) provenientes del cuerpo fiscal, así como las de elaborar prontuarios (condensación de las interrogantes más importantes evacuadas por vía telefónica), manuales operativos, instructivos y circulares. Todos ellos instrumentos tendentes a garantizar la unidad de actuaciones de los Fiscales como principio informador del Ministerio Público, mediante el aseguramiento de una lectura uniforme de la legislación penal vigente y en beneficio de la consolidación de una obligada seguridad jurídica.

Doctrina del Ministerio Público que, a su vez y progresivamente, ha ido conformando una práctica judicial única en todo el territorio nacional, asegurando con ello una interpretación homogénea de la nueva normativa procesal penal ${ }^{31}$.

311 Con respecto a su configuración y estructura orgánica, puede verse Cuéllar Cruz, Rigoberto, La reforma procesal penal y el Ministerio Público en Honduras..., cit., Págs. 178 y 179.

31 Sobre el presente tema, cabe destacar la adopción, por parte del Ministerio Público de Nicaragua, de dicho modelo de unidad de asistencia técnica, denominado Departamento de Asesoría Técnico-Jurídica y con funciones muy similares a las del Departamento de Capacitación y Asesoría Técnico-Jurídica del Ministerio Público hondureño descritas. Proyecro de creación en el cual, para nuestra honra, hemos tenido la oportunidad de participar. 
Finalmente, en tercer lugar y quizás la más importante de las tres, la enorme voluntad de compromiso demostrada por todos los operadores de Justicia. Voluntad que se resume en la toma de conciencia de dos aspectos fundamentales: Que la reforma procesal penal es un reto en el cual esta en riesgo la consolidación de Honduras como un auténtico Estado Constitucional de Derecho; y, la elemental pero trascendental convicción de que se trata de un reto común, a ser afrontado responsablemente por todos los actores e instituciones que vienen obligados por Ley a participar en la misma ${ }^{32}$.

\section{b) Retos}

Ahora bien, visto con merecido optimismo lo anterior, lo cierto es que aún queda mucho por hacer antes de dar por superado el reto de la reforma procesal penal en Honduras.

Así, en primer lugar y entre otros, cabe evidenciar que el nuevo Código Procesal Penal, a diferencia de nuestra antigua normativa procedimental, no es una Ley cuya aplicación pueda ser garantizada mediante la simple lectura literal y memorización de su articulado. Muy por el contrario, se trata de un cuerpo normativo que presupone y requiere de una madurez jurídica que apenas iniciamos a adquirir.

En este sentido, aún queda mucha interpretación por efectuar en cuanto a su lectura, dado que, incluso en aquellos casos donde la claridad de sus preceptos resulte aparente, siempre habrá lugar a interpretaciones diversas, e incluso encontradas, según el punto de vista que cada operador asuma en su aplicación práctica. Por ello, la vigilancia de que dichas interpretaciones en todo caso se realicen de manera sistemáticamente correcta y siempre de forma respetuosa con los principios generales que informan el Código, continuará siendo una constante.

Al respecto, sin duda la política institucional de persecución penal que el Ministerio Público vaya adoptando a través de su actuación a lo largo del proceso, y plasmada en directrices expresas y claras (dictámenes, instructivos, circulares, manuales operativos, prontuarios, etc.), resultará fundamental para continuar consolidando una necesaria práctica judicial coherente y uniforme $e^{33}$.

En segundo lugar, debe resaltarse el grave problema de la limitación material (tanto logística como de personal) de nuestras instituciones del sector Justicia, reflejada en

32 Reflejo constatable de esta voluntad ha sido la conformación de una Comisión Interinstitucional, la que se encuentra representada por los jerarcas de todas las instituciones involucradas en el tema de Justicia Penal y dirigida a coordinar esfuerzos para la correcta y eficaz implementación del nuevo sistema de enjuiciamiento criminal.

33 Debe destacarse que el Fiscal es el actor que ineludiblemente viene llamado a construir, a través de su actuación en el proceso penal, más allá de una simple práctica judicial, la formulación de gran parte de la política criminal nacional; ello, a través de su actuación como integrante de una institución informada por los principios de unidad de actuaciones y dependencia jerárquica y por constituirse en el único sujeto procesal presente a lo largo de todo el proceso penal, desde sus inicios con la denuncia y la investigación, como direcror jurídico de ésta última, hasta la propia ejecución de la sentencia condenatoria en su caso. 
presupuestos muy por debajo de la realidad que les corresponde afrontar, sobre todo ahora con la reciente implementación de un nuevo sistema procesal penal, que si bien resulta indiscutiblemente más oneroso que el anterior, justifica con creces la inversión al examinar sus positivos resultados. Limitación que desgraciadamente significará por mucho tiempo una variable constante, y que nos obliga a racionalizar al máximo los recursos disponibles, no en pocas ocasiones afectando la calidad misma de los servicios que se prestan a la ciudadanía, incidiendo negativamente, en la credibilidad de la misma.

En tercer lugar, sin duda la falta de capacitación de los procuradores en el ejercicio privado de la profesión, como parte fundamental dentro del engranaje del nuevo sistema, resulta una de las más serias preocupaciones actuales a considerar para su completa eficacia.

Problema que, a nuestro parecer, no puede ser eficientemente afrontado únicamente a través de esfuerzos aislados de formación por parte de instituciones como el Colegio de Abogados, con todo el valor añadido que dicho esfuerzo nos pueda merecer; sino que requiere de soluciones mucho más profundas y permanentes, como ser una necesitada reforma a los programas educativos universitarios dentro de los propios planes de estudio de las Facultades de Derecho del país.

Al respecto, y aunque ello pudiese parecer increible para cualquier orro lector no hondureño, debe empezarse por admitir que el Derecho procesal penal, como materia dentro de las ciencias jurídicas, es digna de una atención especializada e independiente de la materia penal sustantiva, con la cual sin duda esta ligada, pero no hasta el punto de minimizarla al grado de simple apéndice de la misma, negándole peligrosamente así su necesario carácter autónomo, y limitándola al estudio rudimentario, no del proceso como ciencia, sino desde una perspectiva aún meramente forense, a través de clases cuyas nomenclaturas así lo reflejan, tales como "practicas", "talleres" o simples "laboratorios" procesales.

No cabe duda que también en este sentido la implementación del nuevo Código Procesal Penal gratamente a significado un abrupto despertar.

Finalmente, en cuarto lugar, y desde una perspectiva orgánica funcional que explicaremos a continuación, resta denunciar el verdadero talón de Aquiles del nuevo proceso penal hondureño: La etapa de investigación.

Como es sabido, la piedra angular del nuevo sistema descansa, no sólo en una nítida distinción de roles procesales entre quien investiga y acusa y quien juzga, sino en una efectiva coordinación entre éstos, y muy especialmente en el necesario binomio que debe existir y mantenerse entre el Fiscal y el agente investigador ${ }^{34}$. De fallar esta relación primaria, poco quedará por esperar en cuanto a los resultados de un proceso basado en una deficiente investigación.

34 Sobre el tema puede verse Cuellar Cruz, Rigoberto, La reforma procesal penal y el Ministerio Público en Honduras..., cit., Págs. 210 y ss. 
$Y$ es, a nuestro parecer, sobre este punto donde radica precisamente el problema del sistema hondureño, en la falta de coordinación real entre el Ministerio Público y la Dirección General de Investigación Criminal. Situación de mal entendimiento que se exteriorizó con toda crudeza durante la crisis interinstitucional sufrida durante el año 2001, y que finalizó hasta el cambio de Gobierno, el cual a su vez trajo consigo el cambio del entonces Ministro de Seguridad, a principios del 2002. Y si bien, y para fortuna del Código, las cosas han mejorado desde entonces, lo cierto es que nada garantiza que dichas pugnas pudiesen resurgir, lo que provocaría una crisis, ya no solo interinstitucional, sino de todo el sistema de Justicia penal, dada la nueva filosofía y estructura del recientemente adoptado proceso penal.

Sobre el tema, resulta importante destacar, que si bien los medios de comunicación, para desgracia de la ciudadanía en general a la cual se mantuvo constantemente en la oscuridad sobre las implicaciones y consecuencias negativas que a sus intereses ello suponía, otorgaron en aquél entonces un tratamiento a la crisis como un mero problema interpersonal entre el Fiscal General y el Ministro de Seguridad; con ello se distorsionó la verdadera dimensión del problema. Y es que nunca se trató, ni se trata ahora, de un simple problema de personalidades, ello seria hacer depender de voluntades el buen funcionamiento de todo un sistema, algo absolutamente inaceptable desde cualquier punto de vista; más allá de esto, se trata de un verdadero problema estructural que debe ser responsablemente afrontado desde esa óptica.

Simplemente expuesto, no existe un mecanismo eficaz mediante el cual un Fiscal pueda dirigirse vinculantemente a un investigador, a fin de cumplir con la función que legalmente le viene encomendada de dirigir jurídicamente la investigación; por lo que la relación de dependencia "funcional", pero no orgánica, establecida en la nueva Ley de la Policía Nacional, y que vino a derogar la Ley del Ministerio Público en lo concerniente a la pertenencia de la Dirección de Investigación Criminal como dependencia del Ministerio Fiscal, ha probado ser en la práctica hondureña, no sólo insuficiente, sino aún más, hipócritamente nefasta ${ }^{35}$.

\section{Futuro de la Reforma Procesal Penal en Honduras}

Una vez justificada la necesidad imperiosa de la reforma procesal penal en Honduras, tanto desde un punto de vista constitucional, como de instrumento de política criminal; y analizados igualmente los logros parciales obtenidos a la fecha, así como los retos aún pendientes; cabe preguntarse qué debe esperarse de la misma en un futuro próximo, o, dicho de forma más propia, hacia donde y para el cumplimiento de que fines debemos orientar nuestra reforma.

35 Un estudio más profundo sobre la problemática planteada, y la necesidad de retomar el tema de una nueva reforma legislativa que devuelva a la Policía de investigación, ya sea al Ministerio Público como mejor opción, o al Poder Judicial, pero en todo caso fuera de la esfera del Ejecutivo, puede verse en Cuellar Cruz, Rigoberto, La reforma procesal penal y el Ministerio Público en Honduras..., cit., Págs. 210 y ss. 
Como ya habíamos tenido oportunidad de sostener en alguna otra ocasión ${ }^{36}$, y al inicio mismo del presente trabajo, lo cierto es que la reforma procesal penal en Honduras, hoy, más que nunca, esta llamada a jugar un papel fundamental como instrumento efectivo para dar respuesta al enorme reto que en la actualidad desgraciadamente representa el constante incremento del fenómeno delictivo en nuestro país. Problemática a la cual, a nuestro parecer, no se le ha podido dar un enfoque debido, experimentando por el contrario con formulas que, lejos de proveer soluciones, parecen incrementar la desesperanza pública al no dar los resultados esperados y prometidos.

En este sentido, habrá que retomar una de las finalidades principales que desde el inicio debió cumplir la instauración del nuevo sistema de enjuiciamiento penal: La de servir como eje central de una política criminal coherente.

$Y$ es que el problema ha residido precisamente en la falta de una verdadera política criminal definida, prevaleciendo, por el contrario, políticas institucionales aisladas, no siempre coincidentes, y lo peor, muchas veces incluso contradictorias. En este sentido, el Ministerio Público ha formulado sus propias políticas institucionales sobre su visión de cómo enfrentar el delito, por su parte, el Ministerio de Seguridad ha seguido los lineamientos que al respecto le han sido informados, a nuestro ver de forma no muy clara, por el Gobierno; y, el Poder Judicial, un poco de lo mismo. Lo anterior, sin sumar los desatinos, algunos a los cuales haremos mención expresa posteriormente, que se han venido cometiendo desde el ámbito legislativo.

Así, por lo menos desde la trascendental perspectiva de los distintos operadores encargados de la persecución penal (Jueces, Fiscales y Policías); el nuevo proceso auxilia a definir un aspecto de suma importancia para la formulación de una política criminal coherente: La nítida delimitación de funciones y atribuciones, es decir, regula perfectamente el rol que cada operador debe cumplir dentro del sistema de Justicia penal. Lo que, a su vez, permitirá no sólo que cada uno se limite a cumplir eficientemente con la específica función asignada (Policía prevenir e investigar delitos, Fiscales dirigir jurídicamente la investigación y velar por el cumplimiento de la labor acusatoria y Jueces juzgar y hacer ejecutar lo juzgado); sino que conlleva el valor agregado de facilitar un siempre necesario control social, simplemente expresado, es un sistema que permite identificar fácilmente cual es el operador que con su indebido o ineficiente actuar esta comprometiendo la correcta impartición de la Justicia penal en su conjunto; facilitando con ello la posibilidad de correctivos, no sólo pertinentes, sino oportunos.

Continuando con esta idea, creemos firmemente que la verdadera fórmula preventiva no esta en incrementar las fuerzas represivas en la calle, ni siquiera en el aumento desproporcionado de penas; sino en poder garantizar que, ante la comisión de un ilícito penal, el Estado tendrá la capacidad necesaria de respuesta para, en primer lugar, llevar a cabo una investigación diligente, y, en segundo lugar, garantizar una

${ }^{36}$ Cuéllar Cruz, Rigoberto, Para enfrentar la delincuencia en Honduras, articulo de opinión publicado en el Diario "El Heraldo" de fecha 12 de enero de 2002, Pág. 7. 
acusación basada en elemento probatorio sólido que no pueda conducir a otra cosa que a un fallo judicial condenatorio.

Es decir, el verdadero mensaje disuasivo para comportamientos criminales no se completa con el temor a posiblemente ser capturado, ni siquiera en la aparente gravedad de la pena que viene legalmente aparejada a la conducta; sino en el temor a un sistema de enjuiciamiento que funciona y tras el cual efectivamente dichas penas son impuestas de forma ejemplificante y con la inmediatez debida, a través de un juicio transparente y público, y aunque lamentablemente ésto pudiese parecer contradictorio para algunos, con todas las garantías a fin de asegurar la confianza ciudadana en cuanto a la culpabilidad o inocencia de aquéllos sometidos al mismo. Y al respecto vale la pena recordar, y tener siempre presente, que todos somos sujetos potenciales de vernos sometidos, justa o injustamente, a un proceso penal.

Hay que comprenderlo debidamente, la función preventiva de la pena no se cumple con el temor abstracto hacia la misma, sino por la posibilidad cierta y segura de su aplicación.

Ciertamente, el actual estado de cosas resulta difícil para todos los que creemos en construir una Honduras como auténtico Estado Constitucional de Derecho, y por tanto apostamos por fortalecer nuestros sistemas democráticos, dentro de los cuales indiscutiblemente se encuentra nuestro actual sistema de Justicia penal, lejos de limitarlos o mermarlos sin meditación seria alguna.

Difícil para los que nos rehusamos a aceptar como respuesta, la instauración de un Estado policial basado en la errónea concepción de que la pretendida seguridad ciudadana, como valor superior, es algo distinto o autónomo a los derechos y garantías individuales que indiscutiblemente la componen, y que traen consigo peligrosas remembranzas a doctrinas que dábamos ya por superadas.

Debe quedar hoy absolutamente claro: En la medida en que se vulnere o limite ilegítimamente el derecho fundamental de una sola persona, se estarán desconociendo los derechos de todos, pues, en definitiva y como ya sostuvimos, ese interés social, entendido como interés general, no es otra cosa que los intereses individuales que lo conforman.

En este sentido, para nosotros la respuesta no esta en sacrificar derechos y garantías en aras de obtener una mal entendida eficacia en la persecución de los delitos, tal y como se pretendió, por ejemplo, con el decreto ejecutivo que autorizaba allanamientos de morada, como regla general, sin autorización judicial o fiscal previa; o en inventar tipos penales que, además de ridículos por inaplicables, van destinados a castigar situaciones de injusticia social imputables, si acaso, a la propia desidia de nuestros Gobiernos, como ser la pobreza o el desempleo ${ }^{37}$; sino en el fortalecimiento de

\footnotetext{
${ }^{37} \mathrm{Al}$ respecto, la vigente Ley de Policía y Convivencia Social, que entro en vigencia el presente año del 2002, es un claro ejemplo de lo anterior.
} 
nuestras instituciones, promoviendo espacios de dialogo que permitan establecer estrategias definidas conjuntas y coordinadas de actuación ${ }^{38}$, así como en el correcto aprovechamiento de la legislación ya vigente y disponible, y sobre todo, al referirnos específicamente sobre el presente tema, a la nueva legislación procesal penal con todas las potenciales ventajas descritas que la misma pudiese ofrecer.

No obstante, igualmente consideramos que aún estamos a tiempo de rectificar, le debemos a nuestra patria, a nuestros hijos, y a nosotros mismos, el intentarlo. Debiendo recordar que la historia es inmisericordiosa, y que juzga no sólo al que con buenas o malas intenciones actúa, sino, y con igual responsabilidad, al que observa, y entendiendo, opta por callar.

\section{Bibliografía}

1. Armenta Deu, Teresa, Criminalidad de bagatela y principio de oportunidad: Alemania y España, Promociones y Publicaciones Universitarias, Barcelona, España, 1991.

2. Barona Vilar, Silvia, La conformidad en el proceso penal, editorial Tirant lo Blanch, Valencia, España, 1994.

3. Binder, Alberto, Diez preguntas básicas sobre política criminal, en la revista jurídica de INECIPH "Justicia y Poder", volumen 1, número 1.

4. Botron Baliña, Pedro M., La conformidad en el proceso penal, editorial McGraw Hill, Madrid, España, 1998.

5. Cabezudo Rodríguez, Nicolás, El sistema de justicia penal negociada en los Estados Unidos de Norte América, editorial Comares, Granada, España, 1996.

6. Cuéllar Cruz, Rigoberto, La reforma procesal penal y el Ministerio Público en Honduras: Justificación y perspectivas (segunda edición actualizada y ampliada), Instituto de Estudios Comparados en Ciencias Penales y Sociales de Honduras (INECIPH), Tegucigalpa, Honduras, 2002.

7. Cuéllar Cruz, Rigoberto, con Caballero Klink, Jesús, y Galán Miguel, Juan Antonio, Las medidas cautelares, "Cuadernos de Estudios Judiciales Rafael Alvarado Manzano", número 8, Corte Suprema de Justicia-Agencia Española de Cooperación Internacional, Tegucigalpa, Honduras, 2001.

\footnotetext{
${ }^{38}$ Como ejemplo de esa correcta orientación, podemos destacar una vez más el trabajo y esfuerzo que se ha venido invirtiendo para la implementación de la nueva normativa procesal penal por parte de la Comisión Interinstitucional de Justicia Penal.
} 
8. Cuéllar Cruz, Rigoberto, Los criterios de oportunidad en el proceso penal: La experiencia hondureña en el marco de su vigencia anticipada al nuevo Código Procesal Penal, revista jurídica de la Unidad Técnica de Reforma

- Penal de la Corte Suprema de Justicia, "Justicia Penal", Año1, número 1, enero de 2002.

9. Cuéllar Cruz, Rigoberto, Para enfrentar la delincuencia en Honduras, artículo de opinión publicado en el Diario "El Heraldo" de fecha 12 de enero de 2002 Pág. 7.

10. De Diego Diez, Luis Alfredo, Justicia criminal consensuada (algunos modelos del derecho comparado en los EE.UU., Italia y Portugal), editorial Tirant lo Blanch, Valencia, España, 1999.

11. Delmas Marty, Mireille, Les grands systèmes de politique criminelle, Presses Universitaires de France, París, Francia, 1992.

12. Pérez Royo, Javier, Curso de derecho Constitucional, Marcial Pons, Ediciones Jurídicas, S.A., Madrid, España, 1995.

13. Tijerino Pacheco, José María, El principio de oportunidad en el ejercicio de la acción penal, en "Reflexiones Sobre el Nuevo Proceso Penal", Imprenta y Litografía Mundo Gráfico, S.A., San José, Costa Rica, 1996.

14. Tocora, Fernando, Política criminal en América Latina, Ediciones Librería del Profesional, Bogotá, Colombia, 1990.

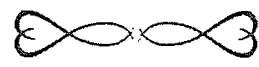

